\title{
Snail, a transcriptional regulator, represses nephrin expression in glomerular epithelial cells of nephrotic rats
}

\author{
Isao Matsui ${ }^{1}$, Takahito Ito ${ }^{1}$, Hidetake Kurihara ${ }^{2}$, Enyu Imai ${ }^{1}$, Toshio Ogihara ${ }^{1}$ and Masatsugu Hori ${ }^{1}$
}

Snail is a DNA-binding molecule that plays a pivotal role in regulating cell adhesion and epithelial to mesenchymal transition. Visceral epithelial cells (podocytes) in kidney glomeruli form a sophisticated cell-cell junction called a slit diaphragm that prevents the loss of plasma protein during ultrafiltration. Nephrin, located in the slit diaphragm and critical for maintaining the integrity of this structure, belongs to the class of cell adhesion molecules of the immunoglobulin super-family. As previously reported, the transcriptional activity of nephrin is a determinant of the integrity of the slit diaphragm in puromycin aminonucleoside (PAN) nephrosis rats. Here, we examined the role of Snail in nephrin expression. In accordance with the downregulation of nephrin in PAN nephrosis rats, Snail was upregulated in vivo and its DNA-binding activity was stimulated in injured podocytes while normal podocytes did not express Snail. An in vitro study demonstrated that Snail bound to E-box motifs in a specific segment of the rat nephrin gene repressed the transcription of nephrin and downregulated nephrin protein. We also found that the expression level of Snail in injured podocytes was regulated by GSK3, which is known to phosphorylate Snail and induce its proteolysis. Pharmacological in vitro and in vivo inhibition studies of GSK3 suggested that GSK3 activity decreased in injured podocytes and this change partially contributed to the decrease in nephrin and increase in Snail and proteinuria. Concordantly, we found that Wnt- 2 was upregulated in injured podocytes and activated the Wnt canonical pathway. As the Wnt canonical pathway inactivates GSK3, it is likely that Wnt-2 accounts for the accumulation of Snail in injured podocytes. In conclusion, Snail is a key molecule, which perturbs the integrity of the slit diaphragm through transcriptional repression of nephrin under pathological conditions. Wnt-GSK3 pathway participates in this mechanism.

Laboratory Investigation (2007) 87, 273-283. doi:10.1038/labinvest.3700518; published online 29 January 2007

KEYWORDS: EMT; GSK3; nephrin; podocyte; Snail; Wnt

Visceral epithelial cells of renal glomeruli, termed podocytes, form highly specialized epithelium in kidney. In normal kidney, loss of plasma protein during ultrafiltration is prevented by the slit diaphragm, which is a unique cell-cell junction between adjacent podocytes. ${ }^{1}$ Recent studies have revealed that injury to podocytes leads to tubular damage and interstitial fibrosis through perturbation of slit diaphragm and resultant proteinuria while severe podocyte injury is an initial step leading to glomerular sclerosis, which is the end stage result of glomerular injury. ${ }^{2}$

The slit diaphragm is comprised of many molecules, such as nephrin, neph 1 and members of the cadherin super-family such as P-cadherin and FAT1. ${ }^{3}$ Among these molecules, human nephrin gene product (NPHS1) is a key constituent which belongs to a cell adhesion molecule class of the immunoglobulin super-family. ${ }^{4}$ Humans with nonsense mutations in NPHS1 $1^{5,6}$ and mice lacking nephrin ${ }^{7}$ manifest podocyte injury with massive proteinuria and effacement of podocyte foot processes. Proteinuric diseases, such as minimal change nephropathy, focal segmental glomerulosclerosis, lupus nephritis, and diabetic nephropathy in human and experimental nephropathy in animals show a perturbation of slit diaphragm and a decrease in the expression level of nephrin. ${ }^{8-18}$ Although null or decreased expression of nephrin is closely related to podocyte dysfunction and proteinuria, little is known about the transcriptional regulation of nephrin.

We previously reported that all-trans retinoic acid drives the in vitro transcription of nephrin through retinoid receptors (RARs) which bind to the promoter region of the nephrin gene as well as exerting anti-proteinuric effects in puromycin aminonucleoside (PAN) nephrosis rats and that

\footnotetext{
Department of Internal Medicine, Osaka University School of Medicine, Suita, Japan and 2Department of Anatomy, Juntendo University School of Medicine, 
vitamin A-deficiency lead to a persistent proteinuria. ${ }^{18} \mathrm{Ne}-$ phrin expression is also under the control of some other signaling pathways in addition to it's regulation by retinoic acids. Wanger et al ${ }^{19}$ found Wilms' tumor suppressor (WT-1) transcriptionally activates nephrin. Doublier et $a l^{20}$ and Langham et $a l^{21}$ reported that glycated albumin and angiotensin II repress nephrin in diabetic patients and that an angiotensin converting enzyme inhibitor prevents nephrin repression. Recently, Benigni et al ${ }^{22}$ demonstrated enhanced nephrin transcription through peroxisome proliferatoractivated receptor gamma $(\operatorname{PPAR} \gamma)$ by pioglitazone, a PPAR $\gamma$ agonist.

This study focuses on the transcriptional regulation of nephrin through the transcriptional regulator Snail, which was originally identified in Drosophila melanogaster as a transcriptional repressor of shotgun, an orthologue of E-cadherin. ${ }^{23}$ Snail represses claudin, occludin ${ }^{24,25}$ and $\mathrm{MUC1}^{26}$ as well as E-cadherin. Transcriptional repression of these molecules occurs through the consensus DNA-binding site for Snail and this site has been reported as the E-box motif $\left(5^{\prime}-\mathrm{CA}(\mathrm{C} / \mathrm{G})(\mathrm{C} / \mathrm{G}) \mathrm{TG}-3^{\prime}\right) .{ }^{27}$ Snail plays a central role in regulating epithelial functions and is critical for triggering epithelial to mesenchymal transition (EMT) in embryonic development, carcinogenesis, and cancer metastasis. ${ }^{28}$

In this study, we examined the involvement of Snail in the transcriptional regulation of nephrin using a rat nephrosis model.

\section{MATERIALS AND METHODS Animals}

Six-week-old male Sprague-Dawley rats were purchased from Japan SLC Inc. (Hamamatsu, Japan), and were maintained at the animal facility of Osaka University School of Medicine. The PAN nephrosis model for podocyte injury was induced by a single intravenous injection of PAN (Sigma, St Louis, MO, USA). PAN was dissolved in saline and administered at a dose of $10 \mathrm{mg} / 100 \mathrm{~g}$ of body weight (wt). In vivo pharmacological inhibition of glycogen synthase kinase 3 (GSK3) was accomplished using $2^{\prime} \mathrm{Z}, 3^{\prime} \mathrm{E}$-6-bromoindirubin$3^{\prime}$-oxime (BIO), a cell-permeable specific GSK3 inhibitor (Calbiochem, CA, USA) or vehicle (DMSO) and these were administered intraperitoneally at a dose of $5 \mu \mathrm{mol} / \mathrm{kg}$ body wt/day once a day from the day of PAN injection to the day of killing. At periodic intervals, rats were anesthetized by intraperitoneal administration of pentobarbital and processed as described previously. ${ }^{18}$ PAN nephrosis is a highly reproducible proteinuric model. On day 5 , all the rats showed marked proteinuria (on the average $61.9 \pm 7.69 \mathrm{mg} / \mathrm{mg}$ creatinine) while normal rats showed a trace amount (on the average $1.27 \pm 0.412 \mathrm{mg} / \mathrm{mg}$ creatinine).

\section{Protein Extraction and RNA Extraction}

Isolated glomeruli were lysed in the cell lysis buffer $(20 \mathrm{mM}$ Tris $\cdot \mathrm{HCl} \quad(\mathrm{pH} \quad 7.5) / 150 \mathrm{mM} . \quad \mathrm{NaCl} / 1 \mathrm{mM} \quad$ EDTA/1 mM EGTA $/ 1 \%$ Triton $/ 2.5 \mathrm{mM}$ sodium pyrophosphate $1 \mathrm{mM} \beta$ glycerophosphate $/ 1 \mathrm{mM} \mathrm{Na} \mathrm{VO}_{4} /$ leupeptin $(1 \mu \mathrm{g} / \mathrm{ml})$ ) (Cell Signaling Technology, Danvers, MA, USA) using a glass/ Teflon homogenizer. RNA was extracted from isolated glomeruli with TRIZOL ${ }^{\mathrm{TM}}$ according to the manufacturer's instructions (Invitrogen, Carlsbad, CA, USA).

\section{Cell Culture and Transfection}

A temperature-sensitive rat podocyte cell line, 2DNA1D7 was originally established by Dr Hidetake Kurihara (Juntendo University, Tokyo, Japan). The cell line was isolated by using nephrin expression as the marker from decapsulated glomeruli of tsA58 transgenic rats, and was cultured in DMEM/ F-12 medium supplemented with 5\% FCS and insulintransferrin-selenium A (Invitrogen, Carlsbad, CA, USA). Cells were cultured at $33^{\circ} \mathrm{C}$ in a humidified $\mathrm{CO}_{2}$ incubator (5\% $\mathrm{CO}_{2} / 95 \%$ air) and passaged for proliferation. The cells were transferred to $37^{\circ} \mathrm{C}$ for induction of differentiation. Owing to the fact that 2DNA1D7 cells proliferate slowly and have low transfection efficiency, normal rat kidney epithelial (NRK52E) cells were used in the experiments requiring higher transfection efficiency. NRK52E cells were cultured in Dulbecco's modified Eagle's medium supplemented with $10 \%$ fetal calf serum (FCS) at $37^{\circ} \mathrm{C}$ in a humidified $\mathrm{CO}_{2}$ incubator ( $5 \% \mathrm{CO}_{2} / 95 \%$ air).

\section{Immunoblot Analysis and Immunohistochemical Analysis}

Antibodies against specific molecules were obtained as follows: HA epitope (Roche, Basel, Switzerland); Snail (AbCam, UK); nephrin (Santa Cruz Biotechnology, CA, USA); WT-1 (Santa Cruz Biotechnology, CA, USA); $\beta$-actin (Sigma, St Louis, MO, USA). An alternative nephrin-specific antibody was also developed in rabbits by immunization with the following peptides: CTLNVKYPAQKLWIEG as well as CEASSLPFELRGHLV and the characterization and purification procedures were performed as described previously. ${ }^{18}$

Figure 1 Nephrin is downregulated and vimentin upregulated in injured glomeruli. (A) RNA isolated from rat kidney glomeruli (control and PAN nephrosis day 5) were subjected to real time PCR analysis. Nephrin expression was normalized to glyceraldehydes-3-phosphate dehydrogenase (GAPDH) expression. Nephrin was repressed at the mRNA level in PAN nephrosis glomeruli $\left({ }^{*} P<0.05\right)$. (B) Nephrin was repressed at the protein level while vimentin expression was enhanced. Glomeruli were isolated at the same time point as (A) and examined by immunoblot analysis using anti-nephrin and anti-vimentin antibodies. For the loading control, the same sample was stained with coomassie brilliant blue because commonly used controls such as $\beta$-actin and $\alpha$ tubulin were upregulated in the glomeruli of PAN nephrosis day 5 (data not shown). Two types of anti-nephrin antibodies were used for the experiments, and gave the identical result. Data using polyclonal antibodies that we prepared is shown. (C) Vimentin immunohistochemistry of control kidney (a) and PAN nephrosis day 5 kidney (b) are shown. Vimentin was predominantly expressed in podocytes and upregulated when injured. 


\section{In Situ Hybridization Analysis}

Sections ( $4 \mu \mathrm{m}$ thickness) were deparaffinized, rehydrated, and further fixed in 4\% PFA/PBS for $20 \mathrm{~min}$ at room temperature (RT). The sections were sequentially incubated in

A

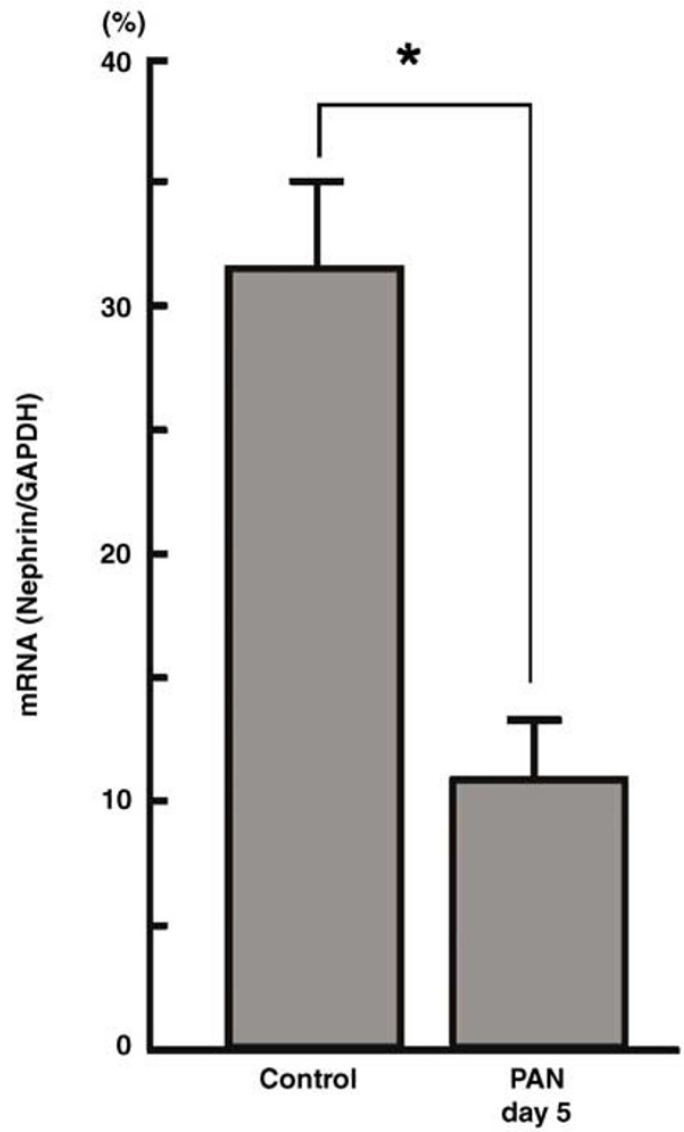

C

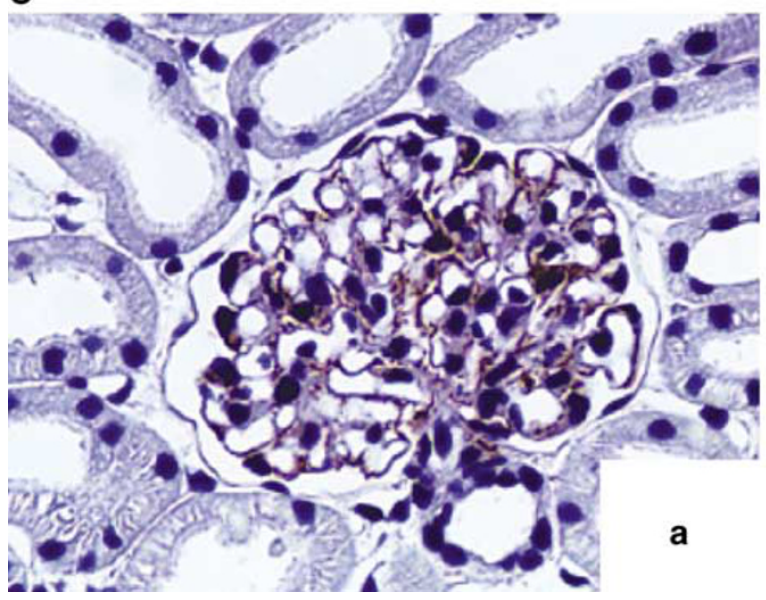

$50 \mathrm{mM}$ Tris $\cdot \mathrm{HCl}(\mathrm{pH} 7.4)$ containing $5 \mu \mathrm{g} / \mathrm{ml}$ of proteinase $\mathrm{K}$ and $5 \mathrm{mM}$ of EDTA for $15 \mathrm{~min}$ at room temperature, in $0.2 \mathrm{~N} \mathrm{HCl}$ for $10 \mathrm{~min}$ at RT, and in $0.25 \%$ acetic anhydride/ $0.1 \mathrm{M}$ triethanolamine for $10 \mathrm{~min}$ at RT. The sections were

B Nephrin (kDa)

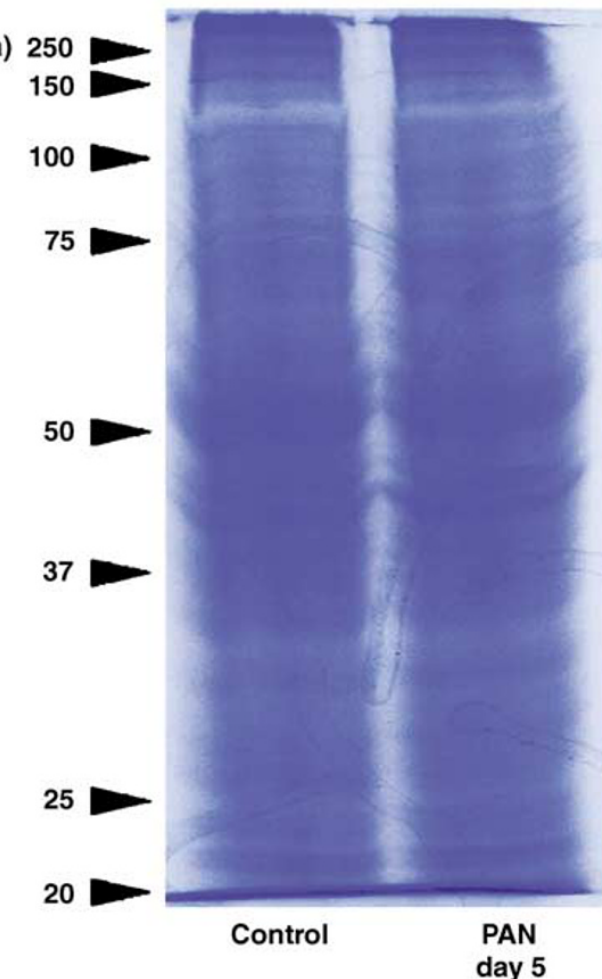

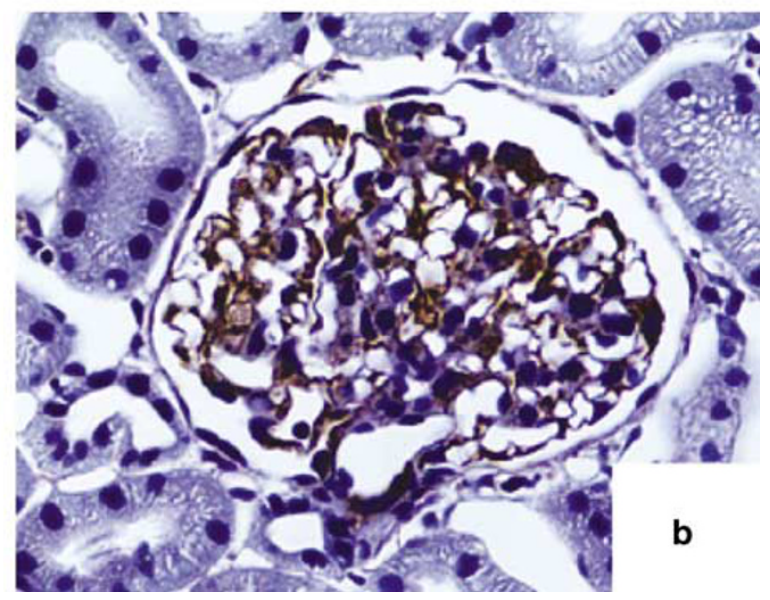


prehybridized with the hybridization buffer $(4 \times \mathrm{SSC} / 50 \%$ formamide $/ 10 \%$ dextran sulfate $/ 1 \times$ Denharde solution/ $2 \mathrm{mM}$ EDTA/denatured salmon sperm DNA $(500 \mathrm{ng} / \mathrm{ml}))$ for $1 \mathrm{~h}$ at $37^{\circ} \mathrm{C}$. Hybridization was performed with $2.5 \mu \mathrm{g} / \mathrm{ml}$ of digoxigenin-labeled cRNA probes in the hybridization buffer at $50^{\circ} \mathrm{C}$. Once hybridization was completed, the sections were washed in $2 \times$ SSC at $50^{\circ} \mathrm{C}$ for $15 \mathrm{~min}$ and were incubated at $37^{\circ} \mathrm{C}$ for $10 \mathrm{~min}$ in $10 \mathrm{mM}$ Tris $\cdot \mathrm{HCl}(\mathrm{pH} 7.5) / 1 \mathrm{mM}$ EDTA/ $0.5 \mathrm{M} \mathrm{NaCl} /$ ribonuclease A $(20 \mu \mathrm{g} / \mathrm{ml})$. Sections were washed twice in $2 \times$ SSC at $50^{\circ} \mathrm{C}$ for $15 \mathrm{~min}$ and twice in $0.2 \times$ SSC at $50^{\circ} \mathrm{C}$ for $15 \mathrm{~min}$ and digoxigenin was immunologically detected using DIG Nucleic Acid Detection Kit (Boehringer Mannheim, Indianapolis, IN, USA). For fluorescent in situ hybridization, fluorescein-labeled nephrin cRNA and digoxigenin-labeled Snail cRNA were visualized with Tyramide Signal Amplification system according to the manufacture's instruction (Perkin Elmer, Fremont, CA, USA).

\section{Quantitative Reverse Transcription-PCR}

To quantify the expression of nephrin mRNA in kidney glomeruli and the podocyte cell line 2DNA1D7, real time SYBR-Green PCR analysis was performed. Briefly, $0.4 \mu \mathrm{g}$ of RNA was converted to single-strand DNA with random primers (Invitrogen) and SuperScript II (Invitrogen). Each cDNA was mixed with $0.5 \mu \mathrm{M}$ of forward and reverse primers, and $12.5 \mu \mathrm{l}$ of GYBR Green Master Mix (Applied Biosystems, CA, USA). PCR was performed with Applied Biosystems 7700 real-time PCR system. The primers sets had the following sequences: Nephrin forward, $5^{\prime}$-GCTCCCAC CATCCGTGC-3'; Nephrin reverse, 5'-GACTATGTCCACA CAACCCCCA-3'; GAPDH forward, 5'-CTCTACCCACGG CAAGTTCAA-3'; GAPDH reverse, 5'-GGATGACCTTGCC CACAGC- $3^{\prime}$. To quantify Wnt-2 expression in glomeruli, the same primer set described below was used.

\section{Semiquantitative Analysis with RT-PCR}

Differential expression of Wnt gene was confirmed by RTPCR. Briefly, each cDNA was mixed with $2 \mu \mathrm{l}$ of $10 x \mathrm{xCR}$ buffer (Takara, Tokyo, Japan), $1 \mu \mathrm{l}$ of dNTP mixture (Takara), $1 \mu \mathrm{M}$ of forward and reverse primers, and $0.1 \mu \mathrm{l}$ of Takara rTaq. PCR was performed with GeneAmp PCR System 9700 (Applied Biosystems, CA, USA). The primer sets had the following sequences:

Wnt-1 forward, 5'-CTGCAGCTACTGAGCCGCAAG-3';

Wnt-1 reverse, 5'-AGTTCCAGCGGCGGTTTCGGA-3';
Wnt-2 forward, 5'-GGTCAGCTCTTCATGGTGGTACA TGAG-3';

Wnt-2 reverse, $5^{\prime}$-CAATGGCACGCATCACGTCTGGGTGT-3'; Wnt-2b forward, $5^{\prime}$-TGGAGGGCACTCTCAGACTTCC- ${ }^{\prime}$; Wnt-2b reverse, $5^{\prime}$-GCCTTGTCCAAGACACAGTAGT- $3^{\prime}$; Wnt-3 forward, $5^{\prime}$-CGCTGGAACTGTACCACCATAG- ${ }^{\prime}$; Wnt-3 reverse, $5^{\prime}$-TGACTGCGAAGGCTACACCAG-3'; Wnt-4 forward, 5'-TCAGGTTGGCCACGCACTAAAGGA GAA-3';

Wnt-4 reverse, $5^{\prime}$-AGTCTGGACTTGGCTCCAGGTACA CC- $3^{\prime}$;

Wnt-5a forward, 5'-CTTCCGCAAGGTGGGCGATGC-3'; Wnt-5a reverse, 5'-TTGCACAGGCGTCCCTGCGTG-3'.

PCR products were separated on a $2.0 \%$ agarose gel, stained with ethidium bromide, and visualized using UV irradiation.

\section{Assay for Transcriptional Regulation of Rat Nephrin Gene}

Rat nephrin gene ( -824 to $+1877 \mathrm{bp})$ was isolated from the rat tail genomic DNA by PCR with the following primers: $5^{\prime}$-AAAGGTACCAGATAAGCAGGCAGCAGGAGT- $3^{\prime}$ and $5^{\prime}$ AAACTCGAGTTGCACACCTGGCTTCGGCCT- $3^{\prime}$. The PCR product was cloned into $\mathrm{KpnI} / \mathrm{XhoI}$-cut pGL3-SV40 vector (Promega, USA) and various fragments of rat nephrin gene $(-824$ to $+403 \mathrm{bp} /+404$ to $+1877 \mathrm{bp} /+404$ to $+1322 \mathrm{bp} /+1323$ to $+1877 \mathrm{bp})$ were subcloned into KpnI/XhoI-cut pGL3-Basic vector by using PCR with following primers:

+403 bp reverse, 5'-AAACTCGAGTACTGGCAGCTTG GATTGTTGAG-3'; + 404 bp forward, 5'-AAAGGTACCAT GGGCGCTAAGAGAGTCACT-3'; + 1322 bp reverse, 5'-AAA CTCGAGCACTCTGGATGAAGGTGATG-3'; + 1323 bp forward, 5'-AAAGGTACCAGTGGGGGTGAACCGGTGGGAT- ${ }^{\prime}$. For pGL3-SV40 constructs with +404 to $+1877 \mathrm{bp} /+404$ to $+1322 \mathrm{bp} /+1323$ to $+1877 \mathrm{bp}$, which contain no core promoter region, segment -300 to $-1 \mathrm{bp}$ was inserted to the $K p n I$ site. Snail-dependent transcriptional regulation of nephrin gene was studied by a slightly modified luciferase assay. ${ }^{18}$ pGL3-SV40 vector carrying various nephrin gene segments $(2.5 \mu \mathrm{g})$ were introduced along with pRL-TK vector $(50 \mathrm{ng})$ and pCAGGSneo HA-tagged Snail $(2.5 \mu \mathrm{g})$ into $2 \times 10^{6}$ NRK52E cells and cultured in a six-well plate. After $24 \mathrm{~h}$, both Firefly and Renilla luciferase activities were measured as described above. Firefly luciferase activities were normalized to the Renilla luciferase activities.

\footnotetext{
Figure 2 Snail is activated in injured podocytes. (A) Immunoblot analysis of Snail is shown. The same sample of Figure 1B was analyzed with anti-Snail antibody. There was a strong signal in the PAN nephrosis day 5 glomeruli, where the control showed no signal. For the loading control, the same sample was stained with coomassie brilliant blue. (B) EMSA for Snail is shown. Nuclear extracts from glomeruli of control rats and PAN nephrosis rats (day 5) were analyzed. The arrowhead indicates the binding activity, which was out-competed by a specific competitor. (C) In situ hybridization analysis was performed with normal rat kidney $(a, c)$ and PAN nephrosis day 5 kidney $(b, d)$ to elucidate the cell that expressed Snail. Snail was localized to injured podocytes but not to normal ones. Red arrows indicate the representative cells (b). For fluorescent in situ hybridization, fluorescein-labeled nephrin cRNA probe (green) and digoxigenin labeled Snail cRNA probe (red) was used. Podocyte marker nephrin was repressed in Snail expressing PAN nephrosis podocytes (d) compared to normal ones (c).
} 
A

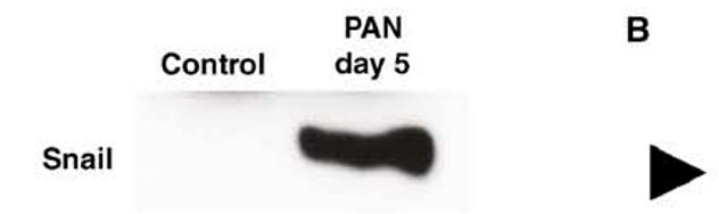

(kDa)

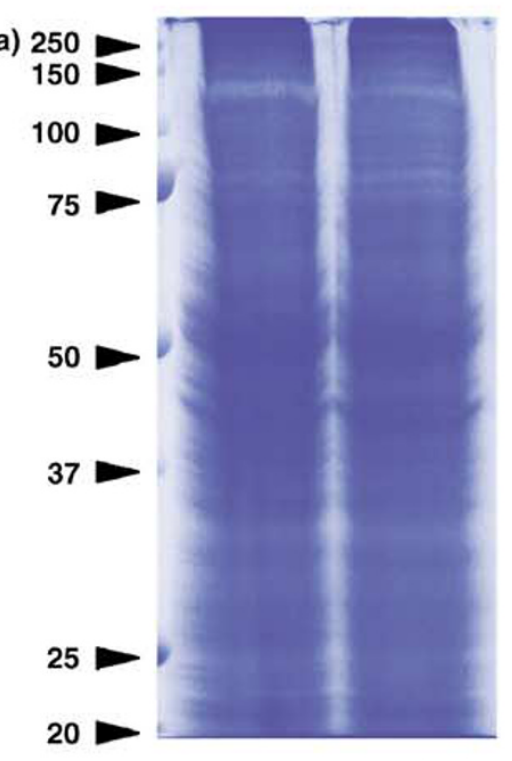

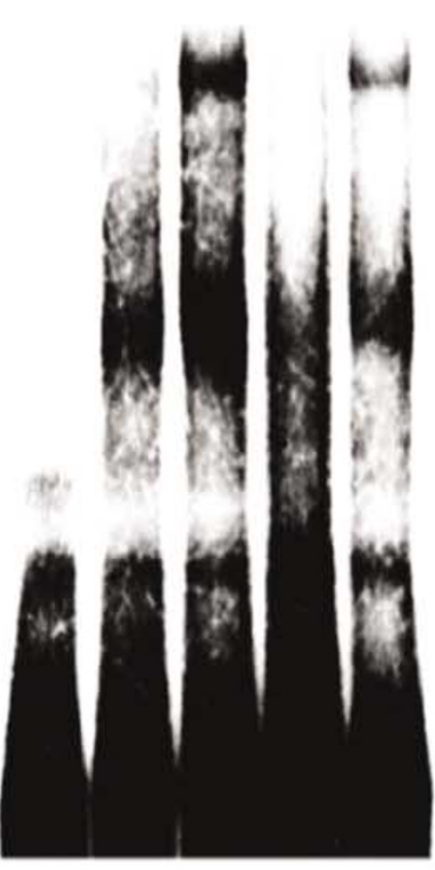

Nuclear Extract (Control) - + - - -

Nuclear Extract (PAN5d) - -+++

Specific Competitor $\quad-\quad-\quad+\quad+$

Non-specific Competitor $\quad-\quad-\quad-\quad+$

C
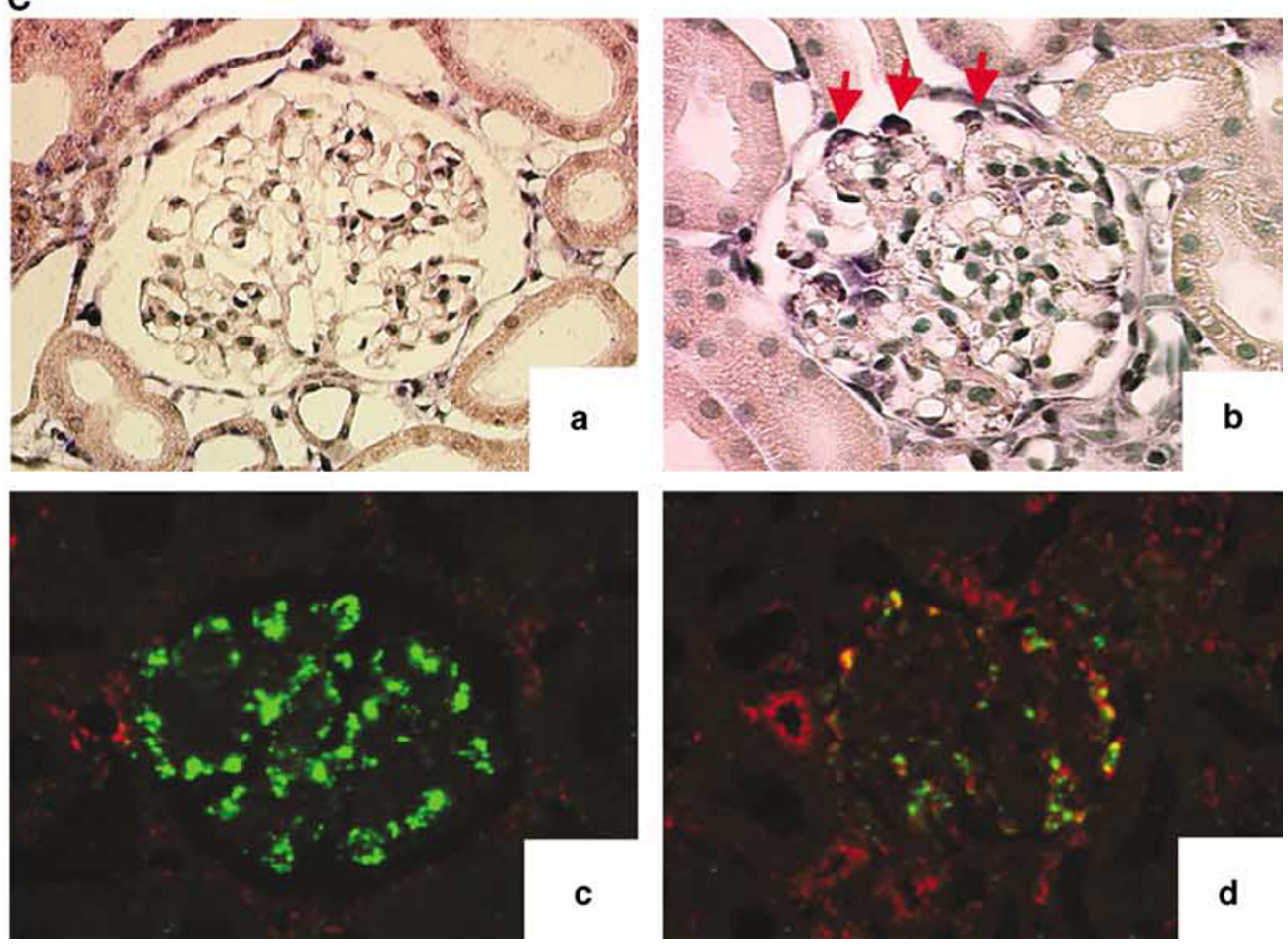


\section{ChIP Assay}

The HA-tagged human Snail expression plasmid or an empty plasmid was transfected into 2DNA1D7 at $33^{\circ} \mathrm{C}$ with Amaxa Nucleofector ${ }^{\mathrm{TM}}$ (Amaxa Inc., Gaithersburg, MD, USA). Chromatin immunoprecipitation (ChIP) assay was performed as described. ${ }^{29}$ Briefly, cells were incubated with $1 \%$ formaldehyde in PBS after $24 \mathrm{~h}$ culture at $37^{\circ} \mathrm{C}$. The cells were washed twice with ice-cold PBS, and suspended in $0.1 \%$ SDS/0.1\% sodium deoxycholate/ $1 \%$ Triton X-100/1 mM EDTA $/ 0.5 \mathrm{mM} \quad$ EGTA/ $140 \mathrm{mM} \quad \mathrm{NaCl} / 10 \mathrm{mM} \quad$ Tris $\cdot \mathrm{HCl}$ (pH8.0) containing protease inhibitors cocktail Complete ${ }^{\mathrm{TM}}$ (Roche Applied Science, Indianapolis, IN, USA). The resultant lysate was sonicated and immunoprecipitated with anti-HA antibody. Finally, DNA associated with the immunoprecipitated protein was evaluated by PCR with the following primers: forward, $5^{\prime}$-AGCTGGGCAGGAGTATG3'; reverse, 5'-TCTGGATGAAGGTGATGT-3'.

\section{Preparation of Nuclear Extract and EMSA}

After the indicated treatment, kidneys were rinsed with icecold PBS and glomeruli were collected as described previously. ${ }^{18}$ Nuclear protein from glomeruli was extracted with Nuclear Extraction Kit (Panomics, Redwood City, CA, USA) according to the manufacturer's instructions. Electrophoretic Mobility Shift Assay (EMSA) was performed with Panomics' EMSA Kit in combination with the probes, specific competitors and non-specific competitors for Snail (Panomics, Fremont, CA, USA) according to the manufacturer's instructions. Sequences of these nucleotides are not disclosed by the manufacturer.

\section{Statistical Analysis}

Statistical significance between experimental values was evaluated by a non-paired $t$-test. Significance was defined as $P<0.05$.

\section{RESULTS \\ mRNA and Protein Product of Nephrin is Down-Regulated in Injured Podocytes}

PAN-induced nephrosis (PAN nephrosis) in rats is a highly reproducible self-limiting disease with reversible podocytes injury. As our data using PAN nephrosis identifies day 5 of disease as the time point when the differential expression of mRNA reaches the maximum, ${ }^{18}$ we employed normal rats and age-matched PAN nephrosis rats. In accordance with previous reports, ${ }^{12,13,15,18}$ nephrin mRNA (Figure 1A) and protein product (Figure 1B) were markedly decreased in glomeruli of PAN nephrosis rats. In contrast, vimentin expression increased in the glomeruli of PAN nephrosis (Figure 1B) and was localized predominantly to podocytes (Figure 1C) and this was consistent with the report from Zou et $a l .^{30}$ These results which are reminiscent of EMT because nephrin is a component of the cell-cell junction among adjacent podocytes prompted us to examine the involvement of the transcriptional regulator Snail in podocytes since Snail promotes EMT. ${ }^{28}$

\section{Snail is Activated in Injured Podocytes and Represses the Transcription of Nephrin}

Immunoblot analysis of glomeruli showed a striking upregulation of Snail in glomeruli of PAN nephrosis rats (day 5) (Figure 2A) whereas control rats did not express Snail (Figure 2A). We examined the DNA-binding activity of Snail by EMSA using nuclear extract of isolated glomeruli and confirmed the strong induction of Snail in glomeruli of PAN nephrosis (day 5) (Figure 2B). In situ hybridization analysis showed that Snail was localized to podocytes of PAN nephrosis (Figure $2 \mathrm{Cb}$ ). In accordance with the result of immunoblot analysis (Figure 2A), mRNA of Snail was not observed in the podocytes of age control rats (Figure 2Ca). In addition to the induction of Snail on injured podocytes, fluorescent in situ hybridization displayed that nephrin was reduced in Snail expressing podocytes (Figure 2Cc, d).

By analogy with Snail-induced repression of E-cadherin, ${ }^{28}$ we investigated whether Snail represses nephrin expression at the transcriptional level. Figure $3 \mathrm{a}$ represents the various segments of rat nephrin gene used for the following experiments with Firefly Dual luciferase assay system. In Figure 3a, +1 denotes the start of nephrin transcription. Each segment flanked by the Luciferase reporter gene was transfected with the pRL-TK control vector and with pCAGGSneo HA-tagged Snail or empty vector into a normal rat kidney epithelium cell line (NRK52E). The results are shown as the ratio of the transcriptional activity of Snail to the transcriptional activity of vector alone (Figure $3 \mathrm{~b}$ ). Snail repressed the transcriptional activity when the longest segment A was used. This repressor activity was found in the segment B2 that include the coding region of rat nephrin but not in the segment $\mathrm{B} 1$ that includes the promoter region of rat nephrin gene. Finally, we found that the segment $\mathrm{C} 1$ was responsible for the repressor activity of Snail on nephrin (Figure 3b). We attempted to further characterize the Snail binding segment in the segment $\mathrm{C} 1$ by using this assay, but were unsuccessful. However, we found five E-box motifs in the segment $\mathrm{C} 1$ to which Snail could potentially bind according to literature (Figure 3c). ${ }^{27}$ All five E-box motifs may be necessary for the association between Snail and nephrin gene.

A rat podocyte cell line was used to prove that Snail binds to the genomic DNA of nephrin and represses nephrin transcription in podocytes. A temperature-sensitive rat podocyte cell line 2DNA1D7 was isolated from decapsulated glomeruli of tsA58 transgenic rats using nephrin expression as the marker. 2DNA1D7 was kept at $33^{\circ} \mathrm{C}$ for proliferation and then transferred to $37^{\circ} \mathrm{C}$ for differentiation. One of podocyte markers WT1 was constitutively expressed in the cells at both 33 and $37^{\circ} \mathrm{C}$ while nephrin was dramatically induced at $37^{\circ} \mathrm{C}$ (Figure 4a). We also confirmed that a podocyte cytoskeleton component $\alpha$-actinin 4 was expressed at both 33 and $37^{\circ} \mathrm{C}$ by RT-PCR (data not shown). As 
a

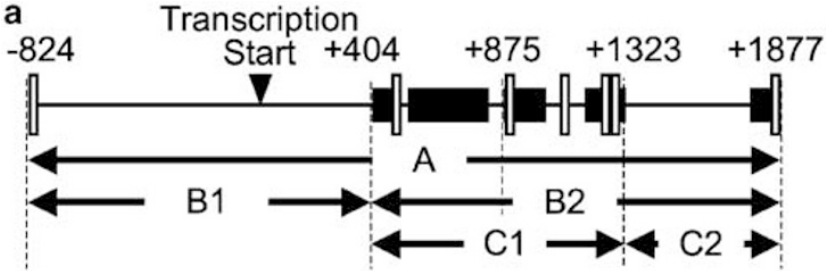

b

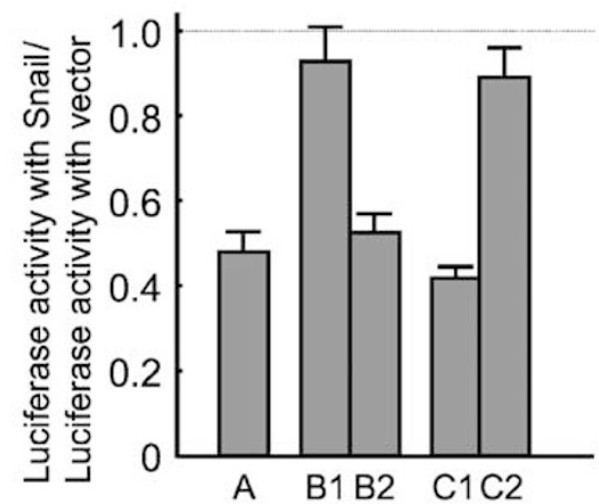

C 441 CAAGCCCAATACACAGAACGTCCAGTTTGACTCCCCTGCT 480 481 GCTCATGGGAATGCTGACC CAGGTA A GTGGAACTCTGGC 520 521 CTTATAGTACACATACCCTCAAGTGTCACCTTGTCTCCTA 560 561 TTGTCAATCTCCTGTGTCCCCAGGCCTGGCCGAGTCGCCA 600 601 GTCCCCACCTCAGCACCTCAAGGC TTCTGGGCTCTGTCTG 640 641 AAAACCTGACTGCGGTGGAAGGGACAACAGTTAAGCTATG 680 681 GTGCGGTGTCAGGGCCCCTGGCAGTGTGGTGCAGTGGGCT 720 721 AAGGATGGGCTGCTTCTGGGTCCAAACC CGAAGATGCCAG 760 761 GCTTCCCGAGGTACAGCCTGGAAGGAGATCGTGCTAAAGG 800 801 TAAGAGATCGGAGTGTGTGATAGTCAGGCACTAGCAGAGA 840 841 CAGTGGCACTGACCTTGGTGGTTCCATCTCCAGGCGAGTT 880 881 CACCTGCTTATTGAAGCCTGTGACCTCAGTGATGACGCA 920 921 GAGTATGAATGCCAAGTCGGCCGCTCAGAGTTGGGTCCCG 960 961 AGCTTGTGTCTCCTAAAGTAATCCTCTCCATTCTAGGTAC 1000 1001 GGGTGAAAGACTCCCCTCCAGGACCCACCAGTCTGGGCGC 1040 1041 CAGCCCTCTTCCCTCAGATCTGGGAGTCCTCTTCCCTCAG 1080 1081 ACTGGGAGTCCTCCACCCTGGGCCCTGGGTACAGTCCCGG 1120 1121 CT TCTAATTTTTTGGCCAAACCCT CACGTGTCTCCCAAC 1160 1161 AATGCTTGATCCCAGACTCTTTCCCACCAGTTTCCCCCAA 1200 1201 GGTGCTTCTGTTGACCCCCGAGGCAGGAAGCACAGTGACC 1240 1241 TGGGTAGCTGGGCAGGAGTATGTGG CACCT TTGTGTCTG 1280 1281 GAGATGCAAAACCAECACCT GACATCACCTTCATCCAGAG 1320 1321 TG

Figure 3 Snail represses nephrin transcription. (a) Segments of rat nephrin gene used for the following experiments are shown, where +1 denotes the start of nephrin transcription. Closed boxes indicate exons and open boxes indicate E-box motifs. (b) Repressor activity of each nephrin gene segment was assayed with Dual Luciferase Assay System. Each nephrin gene construct and pRL-TK control vector was co-transfected with Snail expression construct or empty control vector. The results are shown as the ratio of the transcriptional activity with Snail to the transcriptional activity with empty control vector. The segment $\mathrm{C} 1$ was responsible for nephrin repressor activity with Snail. (c) The sequence of segment C1 is shown. Boxed areas are E-box motifs, which are the putative binding sites of Snail. Arrows indicate the primer sets used for the following ChIP assay (Figure 4b).

expected, Snail was strongly expressed at $33^{\circ} \mathrm{C}$ but almost disappeared at $37^{\circ} \mathrm{C}$ (Figure 4a). ChIP assay using the primer sets shown in Figure 3c (arrows) demonstrated that overexpressed Snail bound to the segment C1 in the cells

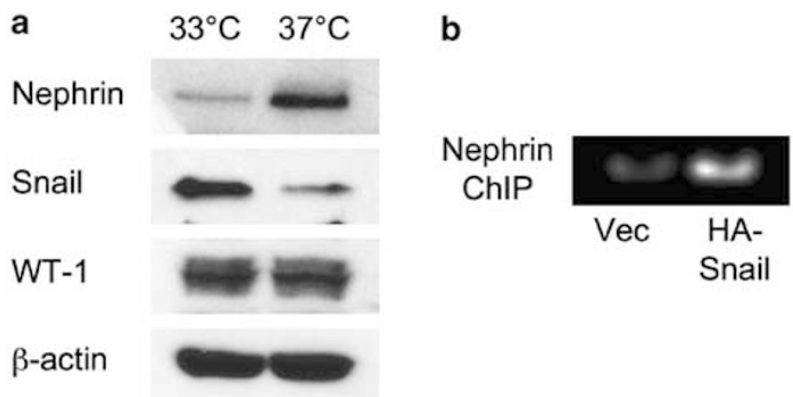

c $(\%)$

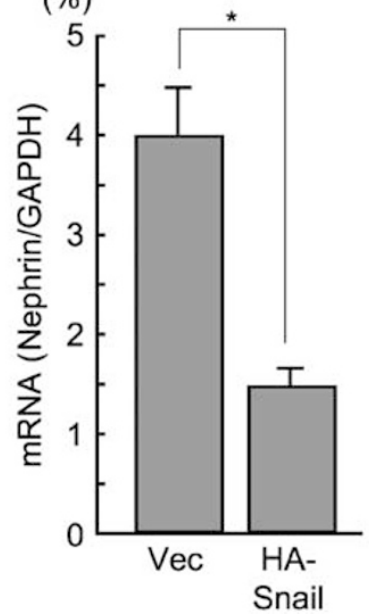

d

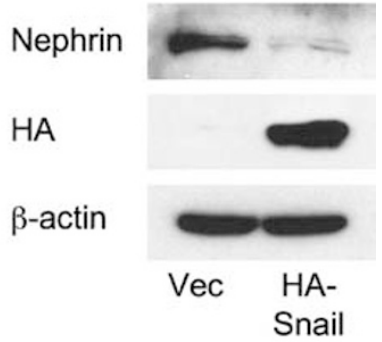

Figure 4 Snail represses endogenous nephrin in podocyte cell line 2DNA1D7. (a) 2DNA1D7 is a temperature-sensitive podocyte cell line, which was isolated by using nephrin expression as the marker from decapsulated glomeruli of tsA58 transgenic rats. This cell line was kept at $33^{\circ} \mathrm{C}$ for proliferation and at $37^{\circ} \mathrm{C}$ for differentiation. Podocyte specific markers were analyzed by immunoblot analysis. 2DNA1D7 cells at $37^{\circ} \mathrm{C}$ upregulated nephrin and downregulated Snail. (b) Snail bound to the segment $\mathrm{C} 1$ of the nephrin gene. HA-tagged Snail-expression construct or control vector was introduced into 2DNA1D7 cells. Then, chromatin immunoprecipitates prepared with anti-HA antibody were subjected to PCR using the primer sets in Figure 3c (arrows). (c) Nephrin expression of 2DNA1D7 cells transfected with empty vector or HA-tagged Snail expression construct was analyzed by real-time PCR. Snail repressed nephrin transcription $\left({ }^{*} P<0.05\right)$. (d) The same sample in (c) was analyzed by immunoblot using anti-nephrin antibody. Endogenous nephrin was repressed by Snail overexpression.

(Figure 4b). The experiment using the antibody against nontagged rat Snail was not successful, possibly because only trace amounts of Snail were expressed at $37^{\circ} \mathrm{C}$. Once overexpressed, however, Snail repressed the transcription of nephrin in the cells (Figure 4c), and was accompanied by a significant decrease in the expression of the nephrin protein product (Figure $4 \mathrm{~d}$ ).

\section{Snail Stabilizing Mechanism is also Activated in Injured Podocytes}

Our results indicate that Snail plays a critical role in regulating the phenotype of podocytes. Therefore, we were interested in the mechanism by which Snail expression levels are regulated in podocytes. It is known that Snail is strictly 
A

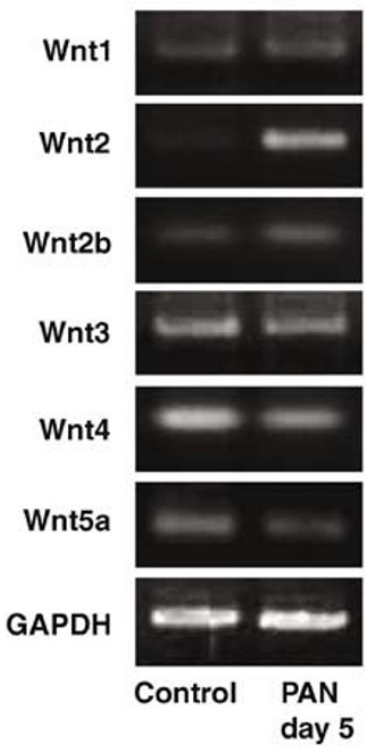

C

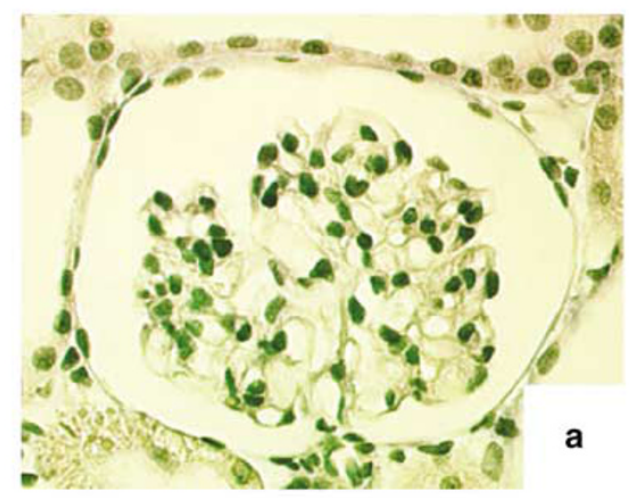

D

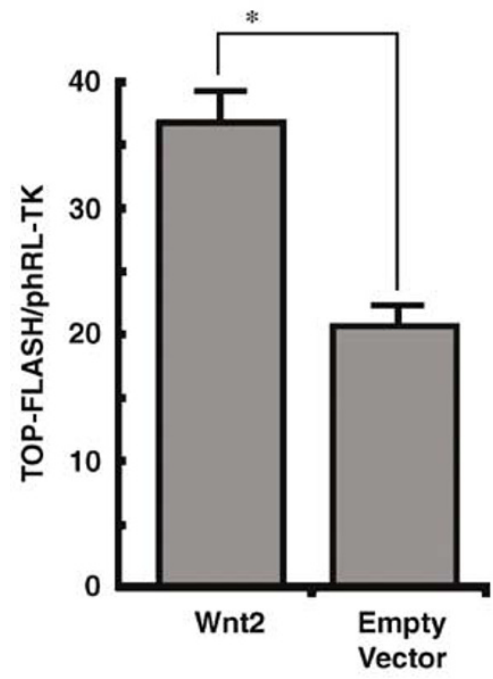

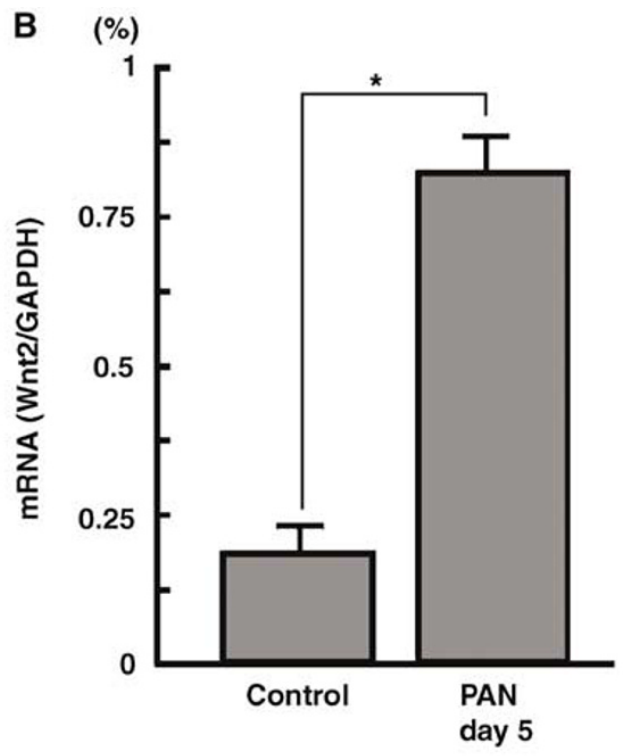

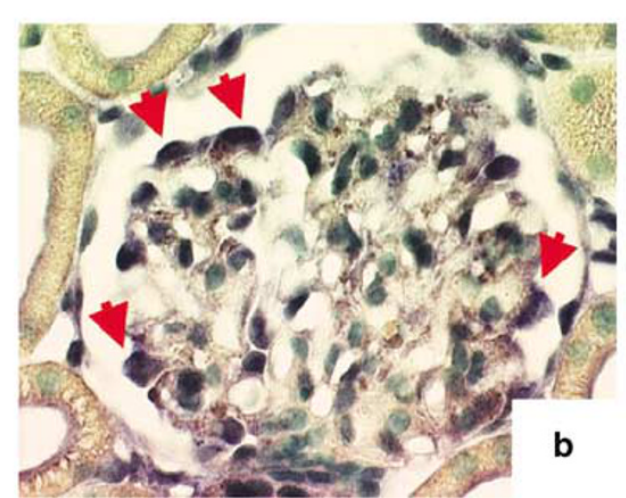

E
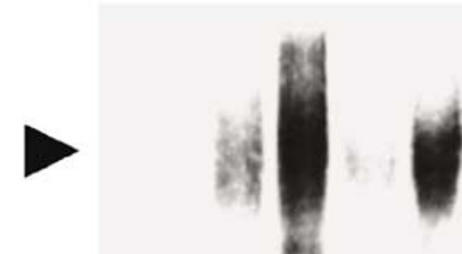

Nuclear Extract (Control)

Nuclear Extract (PAN day 5) - -+++

Specific Competitor

$-\quad-+-$ 
controlled by different signaling molecules such as epidermal growth factor (EGF), fibroblast growth factor (FGF), transforming growth factor (TGF)- $\beta$, bone morphogenic protein (BMP), Notch, parathyroid hormone-related peptide $(\mathrm{PTH}(\mathrm{rP}))$, and Wnt. ${ }^{28}$ Recently, Zhou et al ${ }^{31}$ and Yook et $a l^{32}$ have demonstrated that the stability of Snail protein is regulated by glycogen synthase kinase 3 (GSK3), a downstream component of the Wnt canonical pathway. GSK3dependent phosphorylation of Snail leads to its degradation via the ubiquitin pathway. ${ }^{31,32}$ Based on this knowledge, we further investigated whether the signal transduction pathway from Wnt to GSK3 participates in the regulation of Snail in podocytes.

Semiquantitative RT-PCR analysis for the Wnt family revealed that Wnt-2, a member of the Wnt canonical pathway, was most remarkably upregulated in glomeruli of PAN nephrosis rats (day 5) as compared to glomeruli of control rats (Figure 5A, B). Wnt-4 and Wnt-5a-non-canonical Wnt proteins-were downregulated, and Wnt- 1 , Wnt-2b, and Wnt-3 did not change significantly (Figure 5A). During the time course of PAN nephrosis, mRNA for Wnt-2 reached the highest level on day 5 (not shown). In situ hybridization analysis using PAN nephrosis rats (day 5) showed that Wnt-2 transcript was localized to podocytes (Figure $5 \mathrm{Cb}$ ).

As previously reported, Wnt- 2 activates the Wnt canonical pathway where GSK3 $\beta$ is inactivated and $\beta$-catenin, a wellknown substrate of GSK3 $\beta$ is unphosphorylated. ${ }^{33-35}$ The unphosphorylated form of $\beta$-catenin accumulates in the nucleus and enhances the transcription of target genes in association with the T-cell factor/lymphoid enhancer factor (TCF/LEF) family. ${ }^{36}$ Indeed, using TOP-FLASH assay, a Wnt canonical luciferase reporter, we could confirm the activation of Wnt canonical pathway by Wnt-2 (Figure 5D). Furthermore, EMSA using nuclear extract of isolated glomeruli displayed strong activation of the TCF/LEF complex in glomeruli of PAN nephrosis (day 5) (Figure 5E). This result is consistent with the report that Cyclin D1, a representative downstream molecule of the TCF/LEF complex transcription, was upregulated in podocytes of PAN nephrosis. ${ }^{37}$ These results suggested that the upregulation of Wnt- 2 in injured podocytes leads to the inhibition of GSK3 $\beta$ with the subsequent stabilization of Snail which represses nephrin transcription.

We confirmed by the use of $\mathrm{BIO}(100 \mathrm{nM})^{38}$ or $\mathrm{LiCl}$ $(50 \mathrm{mM})$ which are inhibitors for GSK3, that the activity of GSK3 $\beta$ affects the expression level of nephrin to activate the Wnt canonical pathway in NRK52E and 2DNA1D7 cells.
Snail was expressed at a significant level under the described experimental condition (data not shown). Without the overexpression of Snail as shown in Figure 3b, both BIO and $\mathrm{LiCl}$ markedly suppressed the activity of nephrin transcription through the segment $\mathrm{C} 1$ (Figure 6a, b). BIO and $\mathrm{LiCl}$ also decreased the amount of nephrin protein product when applied to 2DNA1D7 cells (Figure 6c).

BIO treatment of PAN nephrosis rats exacerbated proteinuria (Figure 7a) along with a further decrease in nephrin and increase in Snail expression (Figure 7b). Transcriptional repression of nephrin gene was at least partly responsible for the BIO-mediated decrease in the nephrin protein product (Figure 7c). It should be noted, however, that BIO treatment alone did not induce the expression of Snail or affect the levels of nephrin protein product and it's mRNA (Figure 7b, c).

\section{DISCUSSION}

Our data show that the levels of Snail mRNA and protein are upregulated in podocytes in response to injury (Figure 2), and that Snail acts as a transcriptional repressor of nephrin
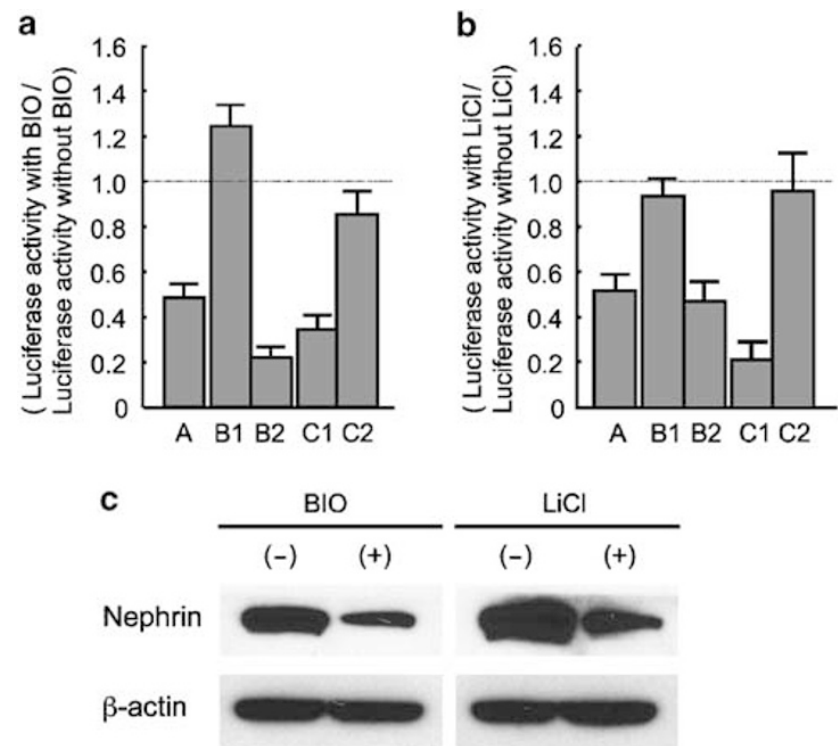

Figure 6 GSK3 inhibitors decrease the expression level of nephrin in vitro. Repressor activity of each nephrin gene segment, used in Figure 3, in the presence of GSK3 inhibitor BIO (a) or $\mathrm{LiCl}(\mathbf{b})$ is shown. Each nephrin gene segment was co-transfected with pRL-TK to NRK52E cells. The value of 'Firefly luciferase/Renilla luciferase' in the absence of the inhibitor was designated as 1.0. (c) Immunoblot analysis of nephrin in 2DNA1D7 cells treated with $\mathrm{BIO}$ or $\mathrm{LiCl}$ at $37^{\circ} \mathrm{C}$. $\beta$-actin was used as the control.

Figure 5 Wnt pathway is activated in injured podocytes. (A) mRNA levels of various Wnt members are shown. RT-PCR products were applied to agarose gel and stained with ethidium bromide. RNA was prepared from glomeruli of control rats (Cont) or PAN nephrosis rats (day 5) (PAN). (B) Wnt-2 mRNA was quantitatively analyzed by real time PCR. (C) Injured podocytes expressed Wnt-2. Control (a) or PAN nephrosis (day 5) kidneys (b) were analyzed by in situ hybridization. The red arrows indicate representative cells. (D) The activation of Wnt canonical pathway by Wnt-2 was confirmed using TOP-FLASH luciferase assay $\left({ }^{*} P<0.05\right)$. (E) EMSA for the TCF/LCF complex, a down stream of Wnt canonical pathway, is shown. Nuclear extract from glomeruli of control rats or PAN nephrosis rats (day 5) was used. The arrowhead indicates the binding activity. 

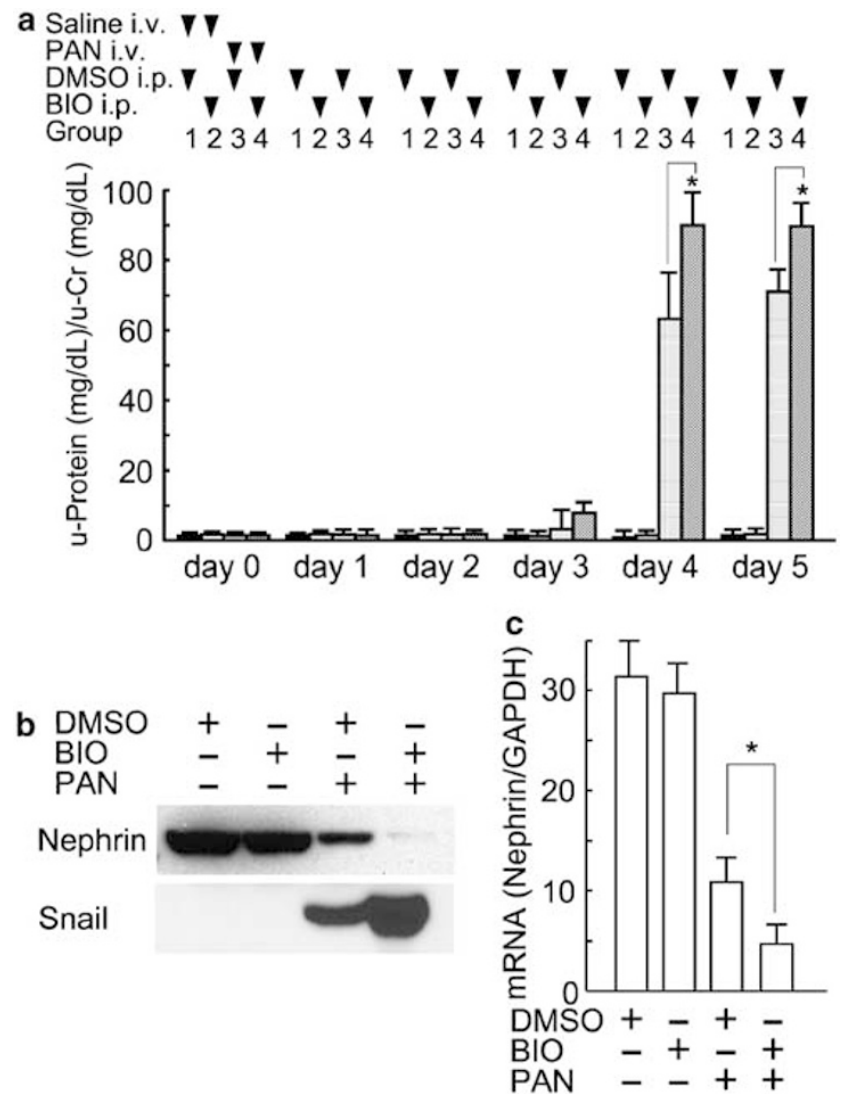

Figure 7 Inhibition of GSK3 in vivo exacerbates proteinuria and leads to the suppression of nephrin. (a) Effects of GSK3 inhibition on proteinuria are shown. A GSK3 inhibitor BIO or vehicle (DMSO) was intraperitoneally administrated once daily for 6 days (day 0-5) to rats with or without intravenous injection of PAN on day 0 . Rats were divided into four groups ( $N=4$ in each group). Groups 1 and 3, DMSO; Groups 2 and 4, BIO; Groups 1 and 2, saline; Groups 3 and 4, PAN. Group 4 excreted much higher amounts of urinary protein than Group 3 on days 4 and $5\left({ }^{*} P<0.05\right)$. Proteinuria was measured as the ratio of urinary protein concentration $(\mathrm{mg} / \mathrm{dl})$ to urinary creatinine concentration (mg/dl). (b) Effects of GSK3 inhibition on the expression levels of nephrin and Snail are shown. Glomerular samples were collected from each group on day 5 and evaluated by immunoblot analysis. (c) Effects of GSK3 inhibition on nephrin mRNA are shown. Glomeruli were isolated at the same time point as (b) and subjected to real-time PCR $\left({ }^{*}<<0.05\right)$.

(Figure 4) through the segment C1 (Figure 3). This pathway at least partly accounts for the phenotypic change of podocytes from normal status to pathological status. The zincfinger domain of Snail may function as the nuclear localization signal as reported. ${ }^{39}$ In genes regulated by Snail, ${ }^{40}$ there is great variation regarding the location of the E-box motifs. In accordance with the segment C1, Snail-mediated repression of claudin-7 is derived mainly from E-box motifs which are located downstream from the putative transcription start point. ${ }^{24}$ At present, all five E-box motifs in the segment C1 are candidates for the association with Snail, but the association of these E-box motifs with non-tagged native Snail remains to be confirmed.
Our data conclusively demonstrates that GSK3 $\beta$ is responsible for the accumulation of Snail in podocytes during PAN nephrosis (Figures 6 and 7). Changes in the activity of the Wnt canonical pathway at least partly account for the inactivation of GSK3 $\beta$ in podocytes (Figure 5). Nevertheless, how the transcription of Snail is initiated in response to injury is unknown. The fact that BIO treatment of normal rats neither induced Snail nor exacerbated proteinuria while BIO treatment of PAN nephrosis rats further upregulated Snail protein product and exacerbated proteinuria (Figure 7) indicates that GSK $3 \beta$-mediated protein stabilization of Snail does not matter under normal conditions. In breast and skin epithelial cells, inhibition of GSK3 induces transcription of Snail. ${ }^{41}$ Therefore, other key events may need to precede the transcription of Snail in injured podocytes. NF- $\kappa \mathrm{B}$ promotes Snail transcription ${ }^{41}$ and DNA-binding activity of NF- $\kappa \mathrm{B}$ is stimulated in cultured podocytes under conditions of increased protein load. ${ }^{42}$ It is plausible that both the activation of NF- $\kappa \mathrm{B}$ and the inactivation of GSK $3 \beta$ are essential for the accumulation of Snail in podocytes. Snail protein product is also stabilized by p21-activated kinase 1 (PAK1) and by a zinc-finger transporter, LIV1. ${ }^{31,32,43,44}$ Currently, we have no data to indicate whether PAK1 and/or LIV1 are involved in the regulation of Snail in podocytes.

The Wnt canonical pathway is not active in normal podocytes (Figure 5). This implies that GSK3 is constitutively active under normal condition. As BIO treatment alone does not induce proteinuria (Figure 7), the biological significance of constitutive activation of GSK3 in normal podocytes remains unknown. By contrast, it is still possible that GSK3 may help podocytes maintain the integrity of slit diaphragm by degrading trace amount of Snail protein. We believe this issue is worthy of further investigation.

In this study, we revealed the role and regulatory mechanism of Snail in injured podocytes and that Wnt-2 and GSK3 are involved in the activation of Snail under pathological conditions.

\section{ACKNOWLEDGEMENTS}

This research was supported by a Grant-in-Aid for Scientific Research from the Ministry of Education, Science and Culture (no. 16390247, 16659050). pCAGGSneo HA-tagged human Snail expression construct was kindly provided by Dr M Ozawa (Kagoshima University, Kagoshima, Japan). We thank Naoko Horimoto for her skillful assistance. All the authors have no conflict of interest to disclose.

1. Huber TB, Benzing T. The slit diaphragm: a signaling platform to regulate podocyte function. Curr Opin Nephrol Hypertens 2005;14:211-216.

2. Kriz W, LeHir M. Pathways to nephron loss starting from glomerular diseases-insights from animal models. Kidney Int 2005;67:404-419.

3. Mundel P, Shankland SJ. Podocyte biology and response to injury. J Am Soc Nephrol 2002;13:3005-3015.

4. Ruotsalainen V, Ljungberg P, Wartiovaara J, et al. Nephrin is specifically located at the slit diaphragm of glomerular podocytes. Proc Natl Acad Sci USA 1999;96:7962-7967.

5. Beltcheva $O$, Martin $P$, Lenkkeri $U$, et al. Mutation spectrum in the nephrin gene (NPHS1) in congenital nephrotic syndrome. Hum Mutat 2001;17:368-373. 
6. Kestilä $M$, Lenkkeri $U$, Männikkö $M$, et al. Positionally cloned gene for a novel glomerular protein-nephrin-is mutated in congenital nephrotic syndrome. Mol Cell 1998;1:1-20.

7. Putaala $H$, Soininen $R$, Kilpeläinen $P$, et al. The murine nephrin gene is specifically expressed in kidney, brain and pancreas: inactivation of the gene leads to massive proteinuria and neonatal death. Hum Mol Genet 2001;10:1-8.

8. Ryan GB, Karnovsky MJ. Distribution of endogenous albumin in the rat glomerulus: role of hemodynamic factors in glomerular barrier function. Kidney Int 1975;8:219-232.

9. Koop K, Eikmans M, Baelde HJ, et al. Expression of podocyte-associated molecules in acquired human kidney diseases. J Am Soc Nephrol 2003;14:2063-2071.

10. Baelde HJ, Eikmans M, Doran PP, et al. Gene expression profiling in glomeruli from human kidneys with diabetic nephropathy. Am J Kidney Dis 2004:43:636-650.

11. Lahdenkari AT, Holmberg C, Koskimies O, et al. Nephrin gene (NPHS1) in patients with minimal change nephrotic syndrome (MCNS). Kidney Int 2004;65:1856-1863.

12. Shibata $S$, Nagase $M$, Fujita T. Fluvastatin ameliorates podocyte injury in proteinuric rats via modulation of excessive Rho signaling. J Am Soc Nephrol 2006;17:754-764.

13. Hosoyamada $M$, Yan $K$, Nishibori $Y$, et al. Nephrin and podocin expression around the onset of puromycin aminonucleoside nephrosis. J Pharmacol Sci 2005;97:234-241.

14. Lee YK, Kwon T, Kim DJ, et al. Ultrastructural study on nephrin expression in experimental puromycin aminonucleoside nephrosis. Nephrol Dial Transplant 2004;19:2981-2986.

15. Guan N, Ding J, Deng J, et al. Key molecular events in puromycin aminonucleoside nephrosis rats. Pathol Int 2004;54:703-711.

16. Luimula P, Sandstrom N, Novikov D, et al. Podocyte-associated molecules in puromycin aminonucleoside nephrosis of the rat. Lab Invest 2002;82:713-718.

17. Kim $\mathrm{YH}$, Goyal M, Kurnit D, et al. Podocyte depletion and glomerulosclerosis have a direct relationship in the PAN-treated rat. Kidney Int 2001;60:957-968.

18. Suzuki A, Ito T, Imai E, et al. Retinoids regulate the repairing process of the podocytes in puromycin aminonucleoside-induced nephrotic rats. J Am Soc Nephrol 2003;14:981-991.

19. Wagner N, Wagner KD, Xing $Y$, et al. The major podocyte protein nephrin is transcriptionally activated by the Wilms' tumor suppressor WT1. J Am Soc Nephrol 2004;15:3044-3051.

20. Doublier S, Salvidio G, Lupia E, et al. Nephrin expression is reduced in human diabetic nephropathy. Evidence for a distinct role for glycated albumin and angiotensin II. Diabetes 2003;52:1023-1030.

21. Langham RG, Kelly DJ, Cox AJ, et al. Proteinuria and the expression of the podocyte slit diaphragm protein, nephrin, in diabetic nephropathy: effects of angiotensin converting enzyme inhibition. Diabetologia 2002;45:1572-1576

22. Benigni A, Zoja C, Tomasoni S, et al. Transcriptional regulation of nephrin gene by peroxisome proliferators-activated receptor-g anogist: molecular mechanism of the antiproteinuric effect of pioglitazone. J Am Soc Nephrol 2006;17:1624-1632.

23. Boulay JL, Dennefeld C, Alberga A. The Drosophila developmental gene snail encodes a protein with nucleic acid binding fingers. Nature 1987;330:395-398.

24. Ikenouchi J, Matsuda $M$, Furuse $M$, et al. Regulation of tight junctions during the epithelium-mesenchyme transition: direct repression of the gene expression of claudins/occludin by Snail. J Cell Sci 2003;116:1959-1967.
25. Ohkubo T, Ozawa M. The transcription factor Snail downregulates the tight junction components independently of E-cadherin downregulation. J Cell Sci 2003;117:1675-1685.

26. Guaita S, Puig I, Franci C, et al. Snail induction of epithelial to mesenchymal transition in tumor cells is accompanied by MUC1 repression and ZEB1 expression. J Biol Chem 2002;277:39209-39216.

27. Muhin V, Luts $Y$, Dennefeld C, et al. Definition of the DNA-binding site repertoire for the Drosophila transcription factor SNAIL. Nucleic Acids Res 1993;21:3951-3957.

28. Nieto A. The snail superfamily of zinc-finger transcription factors. Nat Rev Mol Cell Biol 2002;3:155-166.

29. Spencer VA, Sun JM, Li L, et al. Chromatin immunoprecipitation: a tool for studying histone acetylation and transcription factor binding. Methods 2003;31:67-75.

30. Zou J, Yaoita E, Watanabe $Y$, et al. Upregulation of nestin, vimentin, desmin in rat podocytes in response to injury. Virchows Arch 2006;448:485-492.

31. Zhou BP, Deng J, Xia W, et al. Dual regulation of Snail by GSK-3betamediated phosphorylation in control of epithelial-mesenchymal transition. Nat Cell Biol 2004;6:931-940.

32. Yook Jl, Li XY, Ota I, et al. Wnt-dependent regulation of the E-cadherin repressor snail. J Biol Chem 2005;280:11740-11748.

33. Karasawa T, Yokokura H, Kitajewski J, et al. Frizzled-9 is activated by Wnt-2 and functions in Wnt/beta-catenin signaling. J Biol Chem 2002;77:37479-37486.

34. You L, He B, Xu Z, et al. An anti-Wnt-2 monoclonal antibody induces apoptosis in malignant melanoma cells and inhibits tumor growth. Cancer Res 2004;64:5385-5389.

35. You L, He B, Xu Z, et al. Inhibition of Wnt-2-mediated signaling induces programmed cell death in non-small-cell lung cancer cells. Oncogene 2004;23:6170-6174.

36. Akiyama T. Wnt/beta-catenin signaling. Cytokine Growth Factor Rev 2000;11:273-282.

37. Yu D, Petermann A, Kunter U, et al. Urinary podocyte loss is a more specific marker of ongoing glomerular damage than proteinuria. J Am Soc Nephrol 2005;16:1733-1734.

38. Meijer L, Skaltsounis AL, Magiatis P, et al. GSK-3-selective inhibitors derived from Tyrian purple indirubins. Chem Biol 2003;10: 1255-1266.

39. Yamasaki H, Sekimoto T, Ohkubo T, et al. Zinc finger domain of Snail functions as a nuclear localization signal for importing beta-mediated nuclear import pathway. Genes Cells 2005:10:455-464.

40. De Craene B, Gilbert B, Stove C, et al. The transcription factor snail induces tumor cell invasion through modulation of the epithelial cell differentiation program. Cancer Res 2005;65:6237-6244.

41. Bachelder RE, Yoon SO, Franci C, et al. Glycogen synthase kinase-3 is an endogenous inhibitor of Snail transcription: implications for the epithelial-mesenchymal transition. J Cell Biol 2005;168: 29-33.

42. Morigi $M$, Buelli $S$, Angioletti $S$, et al. In response to protein load podocytes reorganize cytoskeleton and modulate endothelin-1 gene: implication for permselective dysfunction of chronic nephropathies. Am J Pathol 2005;166:1309-1320.

43. Yang Z, Rayala $S$, Nguyen $D$, et al. Pak1 phosphorylation of snail, a master regulator of epithelial-to-mesenchyme transition, modulates snail's subcellular localization and functions. Cancer Res 2005;65: 3179-3184.

44. Yamashita S, Miyagi C, Fukada T, et al. Zinc transporter LIVI controls epithelial-mesenchymal transition in zebrafish gastrula organizer. Nature 2004;429:298-302. 